\title{
Morphology, Origin and Cytogenetics of a 48-Chromosome Panicum maximum
}

\author{
H. Nakagawa ${ }^{1}$ and W. W. Hanna ${ }^{2}$ \\ ${ }^{1}$ Tropical Agriculture Research Center, MAFF, Okinawa, Japan \\ 2USDA-ARS, University of Georgia Coastal Plain Experiment Station, \\ Tifton, GA 31793, USA
}

Accepted March 16, 1990

Guineagrass (Panicum maximum Jacq.) is a highly variable tropical grass native of Africa. Chromosome numbers, such as $2 \mathrm{n}=16$ and 32 (Nakajima et al. 1979), $2 \mathrm{n}=18$ (de Wet 1954), $2 n=32$ and 44 (Moffett and Hurcombe 1949), $2 n=32$ and 48 (Warmke 1951) have been reported for $P$. maximum. Jauhar (1969) discussed the basic chromosome number and evolution of this species. A sexual mode of reproduction has been reported for this species at the diploid $(2 n=16)$ level (Combes and Pernes 1970) while the tetraploid cytotypes are mainly apomictic (Warmke 1954). A forty-eight chromosome Panicum maximum plant was first found in a variety from Puerto Rico by Warmke (1951) who concluded that it was an autohexaploid because up to six hexavalents were found at metaphase I of meiosis. Savidan (1980) obtained hexaploid cytotypes $(2 n=48)$ by crossing artificially doubled sexual tetraploid with an apomictic tetraploid.

The objective of this research was 1) to study morphological characteristics, chromosome behavior, method of reproduction and fertility of 48-chromosome Panicum maximum plants, and 2) to determine the polyploidization and evolution of this cytotype.

\section{Materials and methods}

A $2 n=48$ chromosome plant was selected among open-pollinated progeny of a 32-chromosome obligate apomictic accession (PI298996) which showed winter-hardiness and the potential for excellent production of high quality forage (Hanna et al. 1986). Most surrounding plants had $2 \mathrm{n}=32$ chromosomes.

Seeds were planted in $80 \times 40 \mathrm{~cm}$ flats in the greenhouse. Ten centimeter tall seedlings were transplanted to $5 \mathrm{~cm}$ pots. Six-week old plants were transplanted to the field on $1 \mathrm{~m}$ centers. One, 18 and $172 \mathrm{n}=40-, 32-$ and 48-chromosome plants, respectively were transplanted to the field on May 20, 1986.

Flowering date was recorded when the first inflorescence began anthesis. Plant height was determined on the tallest culm per plant and measured from ground level to the top of the inflorescence. Inflorescence length was determined from 3 inflorescences per plant. Leaf width was measured on the center of the first leaf from the flag leaf on 3 leaves per plant.

Somatic chromosome counts were made from root tips pretreated for 2 hours in monobromonaphthalene, hydrolyzed for 8 minutes in $5 \mathrm{~N} \mathrm{HCl}$ at room temperature and stained in Feulgen solution. Inflorescences were fixed in an acetic acid: ethyl alcohol (1:3) solution for microsporogenesis and in FAA ( $5 \mathrm{ml}$ formalin: $5 \mathrm{ml}$ acetic acid: $90 \mathrm{ml} 70 \%$ ethyl alcohol) for embryo sac studies. Ovaries were dehydrated in tertiary butyl alcohol, embedded in paraffin, sectioned at $12 \mu \mathrm{m}$ and stained in safranin-fast green.

Pollen fertility was estimated by determining the percent stainable pollen with $\mathrm{I}_{2} \mathrm{KI}$.

\footnotetext{
2 Person to whom correspondence should be set. (Telefax number 912/382-8092).
} 
Seed set was determined under both open-pollinated and self-pollinated conditions in the field. Inflorescences were enclosed in glassine bags before anthesis to determine self-pollinated seed set.

\section{Results and discussion}

\section{Morphological characteristics}

Data on morphological characteristics (Table 1) showed that the 48-chromosome plants averaged flowering six days later than the 32-chromosome plants. Plant height was similar for the 32- and 48-chromosome cytotypes. Both cytotypes had similar inflorescence lengths. The 48-chromosome cytotypes had narrower leaves than the 32-chromosome cytotypes.

Table 1. Morphological characteristics of 32-, 40- and 48-chromosome Panicum maximum plants from PI 298996

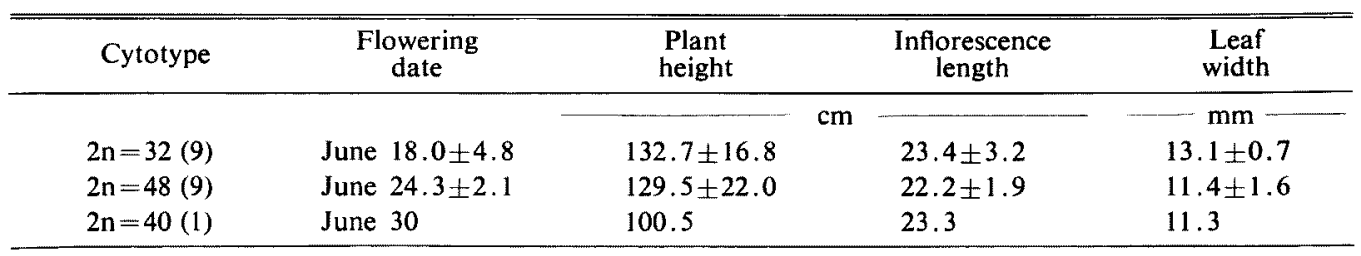

Number in parenthesis is number of plants measured.

Transplanted to field on May 20.

Table 2. Mean and range of metaphase I chromosome associations of 32- and 48-chromosome Panicum maximum plants

\begin{tabular}{ccc}
\hline \multirow{2}{*}{$\begin{array}{c}\text { Chromosome } \\
\text { associations }\end{array}$} & \multicolumn{2}{c}{ Cytotype } \\
\cline { 2 - 3 } & $2 \mathrm{n}=32^{1}$ & $2 \mathrm{n}=48^{2}$ \\
\hline I & $0.06(0-2)$ & $0.13(0-2)$ \\
II & $8.68(2-16)$ & $7.33(1-17)$ \\
III & $0.01(0-1)$ & $0.06(0-2)$ \\
IV & $3.55(0-7)$ & $3.48(0-8)$ \\
VI & 0.00 & $3.08(0-7)$ \\
\hline
\end{tabular}

177 pollen mother cells (PMCs) observed.

: 107 PMCs observed.

Inflorescence length and plant height were not affected by ploidy level. Although measurable morphological differences were recorded among ploidy levels, the differences were small and not readily determined by casual observations.

One shorter $(101 \mathrm{~cm})$ plant was observed among the 48 -chromosome progeny. This plant had 40 somatic chromosomes and flowered six days later than the 48-chromosome plants.

\section{Chromosome behavior and fertility}

Chromosomes paired mainly as bivalents and quadrivalents in the 32-chromosome cytotypes and as bivalents, quadrivalents and hexavalents in the 48-chromosome cytotypes (Table 2). The most frequent associations were $10 \mathrm{II}+3 \mathrm{IV}(26 \%)$ and $7 \mathrm{II}+4 \mathrm{IV}+3 \mathrm{VI}$ $(12 \%)$ for the 32- and 48-chromosome cytotypes, respectively. As many as seven quadrivalents were observed in $4 \%$ of the pollen mother cells (PMCs) of 32-chromosome cytotypes 
indicating these plants are autotetraploids. One to six laggards were observed in $36 \%$ of anaphase I cells of 32-chromosome cytotypes.

Forty-seven different combinations of chromosome associations were observed among 104 PMCs analyzed in 48-chromosome plants. Similar complex chromosome associations were also observed by Warmke (1951) in 48-chromosome plants. Six to seven hexavalents observed in $7.7 \%$ of the PMCs support the autohexaploid nature of these plants. One to eight laggards were observed in $33 \%$ of the PMCs.

Pollen stainability of seven 48-chromosome plants ranged from $65 \%$ to $85 \%$ with a mean pollen stainability of $80 \%$ which was somewhat higher than the pollen stainability of the 40 and 32-chromosome plants (Table 3). The higher pollen stainability of the 48-chromosome plants compared to the 32-chromosome plants is unexpected because of the greater chromosome irregularity at meiosis of the 48 -chromosome plants. Seed set was less than $5 \%$ on the 48-chromosome plants and up to $54 \%$ on the 32 -chromosome plants (Table 3 ).

Table 3. Pollen stainability and seed set on $32-, 40$ and 48-chromosome Panicum maximum plants

\begin{tabular}{cccc}
\hline \hline \multirow{2}{*}{ Cytotype } & $\begin{array}{c}\text { Pollen } \\
\text { stainability }\end{array}$ & Seed set & \\
\cline { 3 - 4 } & & Open-pollinated & Selfed \\
$2 n=32$ & 68 & 52 & 54 \\
$2 n=48$ & 80 & 2 & 5 \\
$2 n=40$ & 68 & nd & nd \\
\hline
\end{tabular}

1 Means of 600 or more pollen grains from 1, 7 and 1, 2n=32, 48 and 40-chromosome plants, respectively.

2 Means of 900 or more florets from selfed inflorescence and 300 florets from open-pollinated inflorescences from each of 1,6 and $2,2 n=32,48$ and 40 -chromosome plants, respectively. $n d=$ not determined.

\section{Method of reproduction}

Embryo sac development in 424 ovules from eight 48 -chromosome plants showed a frequency of $93.1,3.8$ and $3.1 \%$ apomictic, apomictic and sexual, and only sexual embryo sacs in ovules, respectively. Fifty-eight plants established from open-pollinated seed of the 48-chromosome, cytotypes resulted in 56 uniform maternal progeny and two smaller offtypes indicating that some of the sexual embryo sacs function. Similar 48-chromosome plants have been reported for P. maximum by Warmke (1951) and Savidan (1880). Progeny tests by Warmke (1951) indicated the 48-chromosome plants reproduced by obligate apomixis. The occurrence of a 40-chromosome cytotype in open-pollinated progeny of the 48-chromosome cytotype also indicates the functioning of reduced 24-chromosome embryo sacs. The 40-chromosome cytotype probably resulted from the union of a 24-chromosome egg of the 48-chromosome plant with a 16-chromosome sperm from the pollen of a 32-chromosome cytotype (which were predominate in the nursery). The low seed set on 48-chromosome plants (Table 3 ) is partially due to the irregular meiosis and sexual embryo sacs development as well as possibly to embryo-endosperm incompatibilities.

The 32-chromosome accession has been previously reported to be an obligate apomict and to produce uniform maternal progeny (Hanna et al. 1986). The 48-chromosome plant discovered in progeny of the 32 -chromosome accession probably resulted from fertilization of an unreduced egg $(2 n=32)$ in an apomictic embryo sac by a reduced $(2 n=16)$ sperm from the pollen.

This study shows how the fertilization of reduced and unreduced eggs of predominantly apomictic plants allows the formation of plants with new ploidy levels. Reproduction by 
apomixis of the new cytotypes (48-chromosome in this study) allows the survival of the new cytotype in nature even though meiosis is irregular and seed set low.

\section{Summary}

Chromosome behavior, method of reproduction, fertility and morphological characteristics were studied in 48-chromosome plants derived from a 32-chromosome accession (PI 298996) of guineagrass (Panicum maximum Jacq.). Multivalent associations were found at diakinesis and metaphase I which resulted in $33 \%$ of the microsporocytes having one or more laggards at anaphase $\mathrm{I}$. Pollen stainability in $\mathrm{I}_{2} \mathrm{KI}$ ranged from $65 \%$ to $85 \%$. Embryo sac analyses indicated that plants reproduced by a high level of apomixis with some sexual embryo sac development which probably accounts for the occasional off-type plants produced. The 48-chromosome plants apparently originated from the fertilization of a 32-chromosome unreduced egg from an apomictic plant by a reduced 16-chromosome male gamete. The 32- and 48-chromosome plants were morphologically simlar. A 40-chromosome plant resulting from a reduced 24-chromosome egg fertilized by a 16-chromosome male gamete was also found among the open-pollinated offspring from a 48-chromosome plant. The discovery of a 48-chromosome plant in a 32-chromosome accession and a 40-chromosome plant in a 48-chromosome offspring are other examples of the influence of apomixis in formation and maintenance of new cytoypes in nature.

\section{References}

Combes, D. et Perenes, J. 1970. Variations dans le nombres chromosomiques du Panicum maximum Jacq. en relation avec le mode de reproduction. C. R. Acad. Sci., Paris 270: 782-785.

De Wet, J. M. J. 1954. Chromsome numbers in a few South African grasses. Cytologia (Tokyo) 19: 97-103.

Hanna, W. W. 1986. Registration of 12 winter hardy Panicum maximum germplasm clones. Crop Sci. 26: 389-390.

-, Monson, W. G., Dobson, J. W. Jr. and Duncan, R. R. 1986. Dry matter yield and in vitro day matter digestibility of winter hardy Panicum maximum Jacq. selections. Trop. Agric. (Trinidad) 63: $101-104$.

Jauhar, P. P. 1969. Aneuploid alteration of chromosome number in the Panicum mximum complex. Indian J. Genet. and Plant Breed. 29: 342-347.

Moffett, A. A. and Hurcombe, R. 1949. Chromosome numbers of South African grasses. Heredity 3: 369-373.

Nakajima, K., Komatsu, T., Mochizuki, N. and Suzuki, S. 1979. Isolation of diploid and tetraploid sexual plants in guineagrass (Panicum maximum Jacq.). Japan J. Breed. 29: 228-238.

Savidan, Y. 1980. Chromosomal and embryological analyses in sexual $\times$ apomictic hybrids of Panicum maximum Jacq. Theor. Appl. Genet. 57: 153-156.

Warmke, H. E. 1951. Cytotaxonomic investigations of some varieties of Panicum maximum and of $P$. purpurascens in Puerto Rico. Agron. J. 43: 143-149.

- 1954. Apomixis in Panicum maximum. American J. Bot. 41 : 5-11. 